\title{
Diez años en los Proyectos Digitales del Museo Reina Sofía
}

OLGA SEVILLANO PINTADO

Museo Reina Sofía

Permanecemos enfrascados en tiempos inciertos, inmersos en una transformación digital que comenzó ya hace algunos años y que todavía hoy continúa desplegándose. Las herramientas para acompañarla y acompasarse a ella desde una institución cultural como es el Museo Reina Sofía han sido diversas. En este sentido, el presente texto pretende ahondar y reflexionar en los distintos proyectos y mecanismos que se han presentado en el Museo desde mi llegada al departamento de Proyectos Digitales en 2011. Todo el, con la intención de poder abrir un diálogo sencillo y preciso acerca no solo de lo ya elaborado, sino de las futuras posibilidades que podemos seguir haciendo y creando para los demás.

transformación digital, institución, Museo, archivo, arte, proyectos digitales

Transformación digital, interfaces, museos virtuales, videoconferencias, streamings, hipertextos, plataformas, dispositivos, y un largo etcétera de artefactos y conceptos tecnológicos inundan nuestros tiempos. Tiempos convulsos, confusos, excitantes y distópicos que conforman múltiples escenarios y expectativas en este año 2021.

Escribir un texto sobre mi experiencia durante estos diez años en los proyectos digitales del Museo Reina Sofía desde esta intrincada perspectiva actual, conlleva situar la reflexión en un mundo plenamente consciente de la transformación digital. La cual está ya integrada perfectamente en nuestros modos de hacer, nuestras relaciones sociales, nuestros trámites administrativos y nuestros hábitos de consumo.

Durante años, las personas que nos dedicábamos a los proyectos digitales, tanto en su vertiente artística como funcional, nos hallamos en constantes círculos de reflexión, nuevas lecturas y diálogos estimulantes acerca de la transformación inminente que por entonces estaba produciendo la tecnología. Círculos de comunicación, plagados siempre de inquietudes y dudas, que se orientaban tanto hacia la supuesta moralidad de la evolución tecnológica como hacia lo visionario de la misma. Debates que cuestionaban pues sus posibles desbordamientos, con su indudable servicio para determinados avances científicos, pero también las retorcidas desviaciones promovidas por parte de las grandes corporaciones y sus monopolios digitales.

Así pues, el arte electrónico, el informático, el de los nuevos medios, el digital (con la inconsistencia del propio término y la necesidad de derramamiento del mismo), ejemplifican una disciplina adelantada a su tiempo. En realidad, como la del arte en general: siempre visionaria, necesariamente pensativa, experimental y capaz de crear multiplicidad de narrativas y lenguajes 
que nos instan a reflexionar por encima de los márgenes políticos, la globalización cultural y los medios de comunicación más tradicionales.

Con todo ello, mis comienzos en los proyectos digitales del Museo Reina Sofía en el año 2011 constituyeron una oportunidad, pero también un fuerte compromiso. La responsabilidad, tan atractiva, de poner en valor mi manera de entender las bondades de Internet, en una visión prometedora, llena de posibilidades y con la disposición de la tecnología. Todo ello, me permitía conformar la versión digital de un Museo que estaba llevando a cabo una trayectoria histórica en cuanto a proyectos expositivos, programa académico y actividades.

Los inicios para todo el recorrido posterior estuvieron claros: debíamos partir primero de la construcción, tan necesaria, de una página web sólida y completa. En ella, el diseño y la usabilidad se centrarían tanto en la creación de un archivo sobre el propio programa de la institución, desde sus inicios hasta la actualidad; como en la búsqueda por promover un acceso claro, rápido y atractivo a la exigente programación en curso que emergía desde los diferentes departamentos del Museo y que articulaba su discurso de "público-misión-museo" desde múltiples perspectivas.

De esta manera, con esta premisa básica para la reconstrucción de la memoria del Museo, pusimos en marcha un trabajo insólito de cooperación entre las distintas áreas, donde tuvimos que recuperar todos aquellos archivos que nos permitieran elaborar fichas de cada una de las exposiciones y actividades, también con sus materiales complementarios y/o derivados; esto es, los correspondientes catálogos, las hojas de sala, los folletos informativos, las fotografías y los vídeos... Una tarea ardua y compleja que nunca hubiera sido posible sin la ayuda y la complicidad de las personas que trabajaban por aquel entonces en los distintos departamentos, destacando muy especialmente a aquellos comprendidos en Actividades Editoriales, Actividades Públicas y en Exposiciones. Tampoco, sin la inestimable voluntad de las personas cuya amplia trayectoria en el Museo permitieron ofrecer un criterio selectivo y memorístico, el cual permitió seleccionar un fidedigno archivo documental para cada uno de los acontecimientos expositivos (por entonces se contaban más de quinientas exposiciones) y ciclos de actividades (con alrededor de trescientos eventos). Casi sin darnos cuenta estábamos iniciando un trabajo colaborativo interdepartamental y transversal que acabaría sentando un sólido precedente para futuros proyectos.

Entonces, habían pasado ya seis años desde esa experiencia de cimentación y desarrollo de la web principal del Museo. Junto con ello, habíamos ido adquiriendo nuevas experiencias para asentar una metodología de proyectos que involucraban a diferentes perfiles -desde el más académico hasta el eminentemente técnico- desde los inicios hasta la publicación final de los trabajos. También habíamos conseguido desarrollar una cuidada producción de vídeos y un novedoso programa de radio con artistas y colaboradores que permitía complementar y acompañar con otras lecturas, la visual y la acústica, a la programación propia del Museo. En definitiva, contábamos pues con la energía y la disposición necesaria para abordar otro tipo de retos digitales con los que poder seguir rebasando las salas expositivas, buscando crear otras miradas y relatos a través de la documentación resultante de conjuntos documentales que provenían de las líneas-fuerza de investigación que se habían abierto en la institución. 


\section{Repensar Guernica y la idea de archivo}

Fue hace cuatro años cuando el Museo Reina Sofía, para celebrar el 80 aniversario de la creación del Guernica (1937) de Pablo Picasso, organizó una gran exposición en torno a dicha obra y publicó dos catálogos diferentes en colaboración con prestigiosos especialistas.

De forma paralela a esta exposición, se inició también un ingente proyecto de investigación llamado "Fondo Documental Guernica", con el propósito de reunir y estudiar el mayor número de documentación y referencias posibles (correspondencia personal e instituciones de la época, fotografías, diversos documentos gráficos, nuevas creaciones y versiones audiovisuales y plásticas) en relación a la pieza más emblemática de la Colección del Museo.

Por otro lado, el departamento de Conservación y Restauración de la institución había iniciado desde años atrás una ambiciosa tarea de digitalización de la obra. Ésta consistía en la instalación en la sala de un novedoso robot, hecho a medida para que abordase sin problema las especiales dimensiones del cuadro, que permitía llevar a cabo un estudio técnico de la obra sin precedentes. Tiempo después, y tras la obtención de este gran volumen digital de miles de capas de imágenes distintas del Guernica, el reto estaría en poder desarrollar un software capaz de que esas imágenes en altísima resolución en gigapíxel pudiesen navegarse en una página web de forma libre y abierta.

Y así, nació entonces nuestro proyecto web "Repensar Guernica”.

Un completo equipo de investigadoras, programadores, editores de texto, traductores, asistentes de derechos de autor, diseñadores gráficos, desarrolladores de interactivos y programadores, conformó esta colosal idea que se acabó extendiendo a lo largo de dos años hasta su publicación final en noviembre de 2017. La base del proyecto la conformaba el "gran archivo de archivos", con más de 2.000 documentos procedentes de unos 120 archivos del mundo, permitiendo que la investigación textual se convirtiera en una indagación rizomática.

Para permitir el acceso a este gran archivo digital, en tanto que proyecto colectivo y coral, desarrollamos varias herramientas de navegación en la web: un potente buscador, una cronología precisa, unos itinerarios concienzudos y un archivo oral siempre necesario. Con el buscador permitíamos la búsqueda libre de términos, y dado que todos los documentos contienen varias etiquetas, los itinerarios y las opciones de búsqueda constituyen y visibilizan las múltiples vías y caminos propuestos para la consulta del archivo, cada una de las cuales devuelve la posibilidad de una experiencia siempre distinta. La cronología, por su parte, nos facilitó contar con un recurso visual, limpio e interactivo, que constituía otro motor de búsqueda dentro de la web. Asimismo, conformamos también una serie de itinerarios y relatos alrededor de grandes ejes temáticos que contribuían a contextualizar la obra.

Con todo ello, nuestro propósito no estaba en crear grandes niveles de interés o autoridades concretas, tampoco en priorizar un año determinado o un episodio, ni en construir una lectura dominante del archivo, sino en favorecer una lectura plural, otorgando a todos los documentos la misma actualidad y vigencia, permitiendo que participaran de igual forma en esa elaboración de relatos prevista gracias a las numerosas etiquetas. Así pues, el proyecto "Repensar Guernica" no contiene una única historia, sino múltiples, al fin y al cabo, tantas narraciones como usuarios tracen su ruta dentro de la web. Siendo todas ellas válidas y complementarias, siendo todas ellas necesarias.

Repensar Guernica nos permitió pues experimentar con la idea de archivo y también ampliarla, en una intención que hemos reforzado recientemente con una nueva sección: 
"Contra-archivos (im)posibles". Basada en una investigación encomendada a Francis Frascina, profesor de Artes Visuales de la Universidad de Keele, esta nueva fragmentación ofrece un extenso mapa de relaciones y conexiones que parten de la distinta resignificación política que varios colectivos estadounidenses de artistas (y activistas) hicieron del Guernica en dos momentos históricos concretos: las guerras de Vietnam y de Irak.

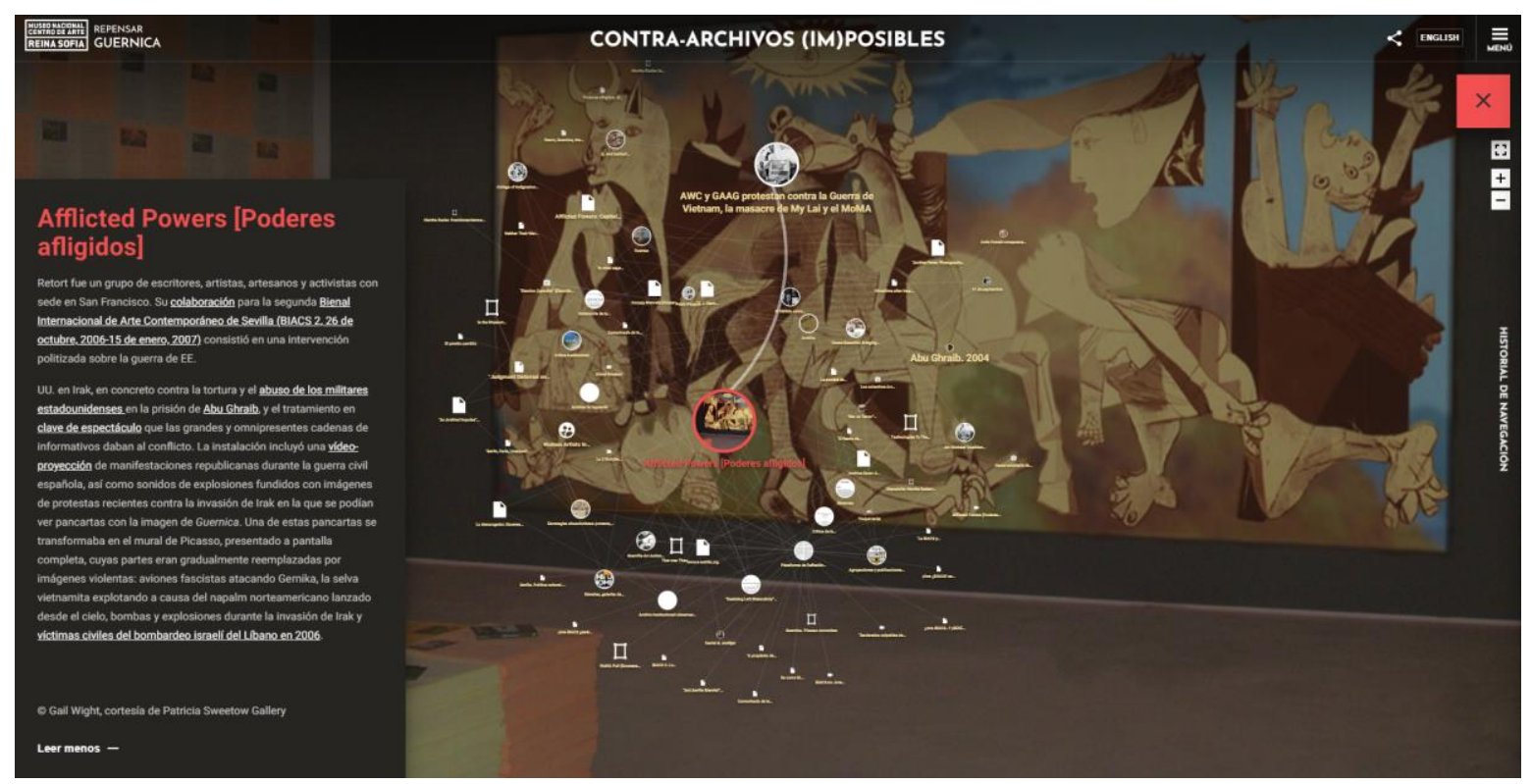

Fig 1. Imagen Contra-archivos (im)posibles

En "Contra-archivos (im)posibles" hemos continuado cuestionando el concepto de archivo en tanto que repositorio universal y exhaustivo de documentos, información y conocimiento. Al partir de esta premisa, y como contrapunto al buscador inicial de documentos, pusimos en valor una propuesta interactiva con una representación gráfica novedosa que "demostraba" que todo archivo está siempre incompleto y abierto a la crítica.

\section{RRS - La Radio del Museo Reina Sofía y el canal de vídeo}

Inaudible, Redes, Contextos y Procesos. Estos son los nombres de los cuatro canales de la radio web del Museo, la cual contiene en la actualidad más de 11004 minutos de audio repartidos en 250 cápsulas distintas. Todas ellas, en su conjunto, conforman un universo compuesto por las identidades acústicas de cada una de las propuestas.

Con un equipo de trabajo que está íntegramente formado por artistas sonoros del estado español, y aunque con claras influencias de la RWM (Radio Web MACBA), esta radio se propone como una versión sonora original de la institución. Capaz de seguir desenvolviendo todo aquello presentado en la programación del Museo, en una vertiente sonora necesaria y que supone un espacio de ampliación para el público especializado. Las cápsulas de la radio proponen así entrevistas relacionadas, contextos sonoros prácticamente desconocidos, obras de arte plenamente acústicas y, en general, espacios de reflexión sobre cuestiones que todavía permanecen levemente sumergidas. 
Asimismo, la personalidad de cada uno de los autores y autoras que proyectan estas cápsulas de radio acaba impregnándolas en su totalidad. Se conforman pues territorios personales que son también profundamente artísticos, y que contribuyen a que las obras de arte no cuelguen tanto de las paredes y se desplieguen entre sus contornos.

\section{\begin{tabular}{l|l|l|l|l|l|l} 
RRS Redio del Museo & Explorar & Canales - & Buscar en la radio.. & a & Acerca de & English
\end{tabular}}

¿Qué es la Radio del Museo Reina Sofía?

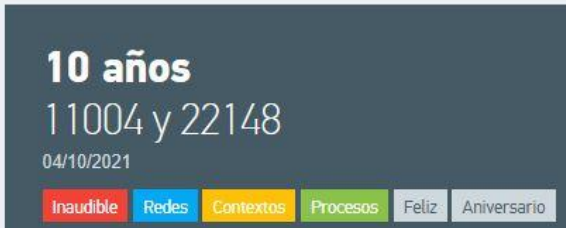

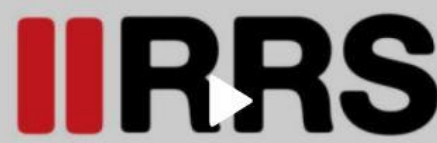

Radio del Museo Reina Sofía

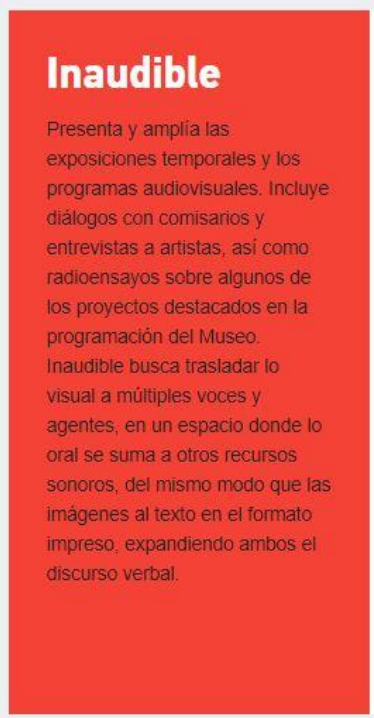

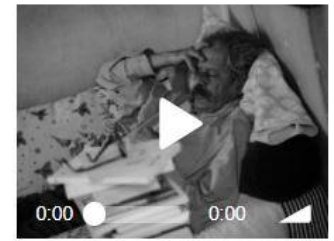

Entre la memoria y el

trance

Una aproximación sonora a

Trilogía Marroquí

26/07/2021

Inaudible Cuerpo Experimentación

Historia Música Poscolonialidad

Sonido

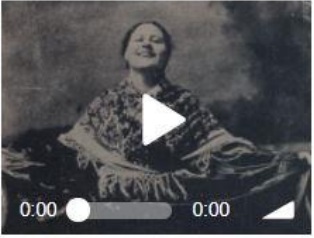

Sicalípticas, vanguardistas $\sin$ saberlo

Con la peor doble intención, 1907 $-1940$

04/03/2021

Inaudible Música Historia

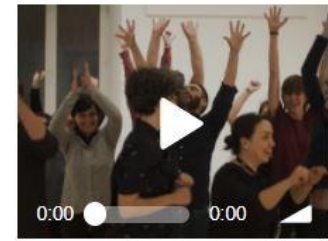

Relatorías sonoras de la Escuela Perturbable $01 / 06 / 2020$

Inaudible Experimentación Pedagogla Museo Cuerpo Espacio

Fig 2. Imagen Radio del Museo Reina Sofia

Este carácter artístico es palpable también en los numerosos proyectos audiovisuales que proyectamos y gestionamos. En todos ellos existe una profunda huella creativa que queda visible en las piezas, y que parte tanto de la cercanía con los creadores, como con la necesidad de desarrollar líneas estéticas condensadas y favorecer la libertad creativa. Algo fácilmente visible, por ejemplo, desde los videos más "sencillos", como son las entrevistas a distintos artistas y creadores y que se sigue desarrollando en los pequeños video ensayos que acompañan a las actividades programadas por el Museo. Una inquietud creativa y personal que acaba tomando una forma sublime en composiciones más complejas como son los videos creados a propósito de ciertas exposiciones celebradas en el Museo y artistas de la Colección, como es el caso de Richard Hamilton o, finalmente, el documental realizado sobre la figura de Elena Asins. 
Unas cápsulas de radio y unos videos que componen además un papel fundamental en nuestros destacados de la Colección, como pueden ser el de "Fuera del canon. Las artistas pop en la Colección" y "Frente y retaguardia: mujeres en la Guerra Civil”, ambos presentados con motivo del Día de la Mujer en estos dos últimos años. En ellos se observa también ese interés por la investigación y la recopilación de lo que todavía no es visible y consideramos necesario traer al presente. Fotografías, obras artísticas, revistas, libros, nombres... Toda una recapitulación que continúa con las principales líneas de investigación del Museo y que encuentra en nuestra web el espacio propicio para seguir creciendo y expandiéndose.

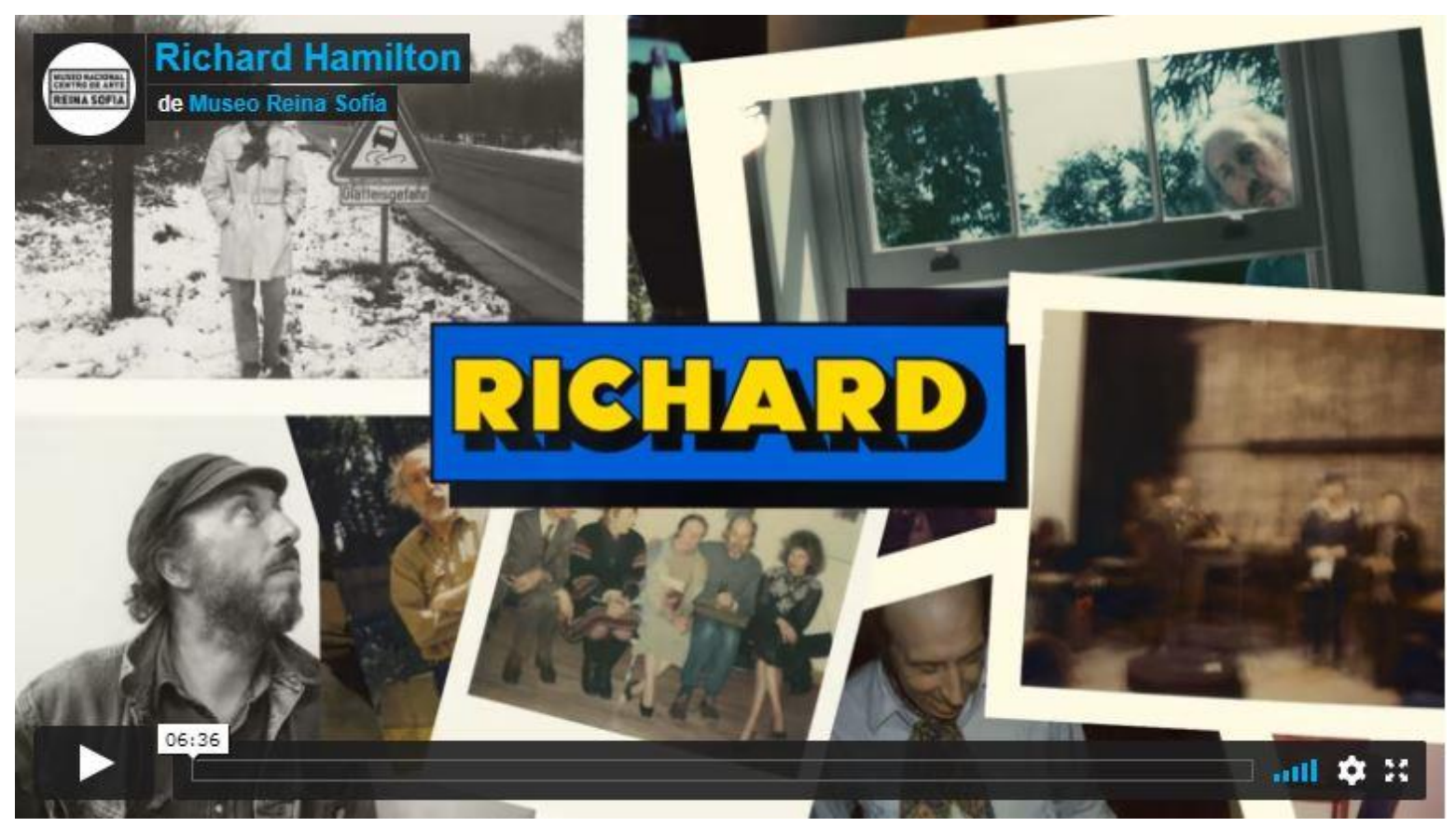

Fig 3. Imagen del video de la exposición a Richard Hamilton

\section{Tiempos inciertos}

Una oportunidad, ésta, la de seguir creando nuevos proyectos y posibilidades que de ninguna forma puede ser despreciada o tomada a la ligera. Existe la necesidad de seguir tejiendo y entretejiendo nuevas líneas de investigación que promuevan una lucha sincera contra el egoísmo, buscando nuevas maneras de colaborar entre todas y de seguir contagiándonos de otras maneras de crear capaces de subvertir nuestros modos de pensar, de ver, de escuchar.

Lo digital se convierte, por tanto, en una atmósfera compleja, siempre abierta al cambio constante, siempre sorprendiéndonos, quizá incluso asustándonos. La viabilidad de nuestras aportaciones siempre se encuentra en disputa, al límite, ocasionando unas ansiedades que no todos pueden llegar a comprender. Sin embargo, es este mismo movimiento, el que lo convierte en un espacio atractivo, natural a las ampliaciones y a los nuevos acuerdos. Así pues, mantengo todavía esa doble sensación de la que hablaba y con la que comencé mi andadura en proyectos digitales en el Museo ya hace más de diez años: la de la oportunidad positiva, energética, pero también, la de compromiso adquirido para con, Internet, y para con todos los que acompañan, los demás. 
Sobre la autora

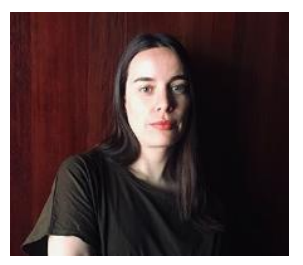

OLGA SEVILLANO PINTADO

Responsable de Proyectos Digitales del Museo Reina Sofía

Olga Sevillano Pintado es Licenciada en Historia del Arte por la

Universidad Autónoma de Madrid. Diploma en Crítica de Arte por la

Fundación Claves del Arte y Máster en Comisariado y Prácticas Culturales

en Arte y Nuevos Medios por MECAD/ESDI y Universidad Ramón Llull de

Barcelona. Entre sus trabajos de gestión y coordinación de eventos de

Arte y Nuevas Tecnologías destaca, en el año 2011 el Comisariado del $12^{\circ}$

Festival Internacional de Investigación Artística de Valencia Observatori y en 2010, la coordinación de la exposición Sueños de Silicio: Arte, Ciencia y Tecnología en la Unión Europea con motivo del Consejo Informal de Ministros para la Presidencia de España en la Unión Europea.

Desde el año 2011, es responsable de los Proyectos Digitales del Museo

Reina Sofía: coordinación, gestión y desarrollo de la página web del Museo www.museoreinasofia.es, la RRS Radio del Museo Reina Sofía https://radio.museoreinasofia.es y página web https://guernica.museoreinasofia.es, ganadora de un premio internacional Webby 2018 a la mejor web de una Institución Cultural. Asimismo, desde 2012 realiza charlas y talleres relacionados con los Museos y su papel en el contexto digital. 